\title{
Cultura visual, gênero e embalagens de jogos de ciência: (Como) meninas brincam de ciência?
}

\author{
Visual culture, gender and packaging science \\ games: (How) girls play science?
}

\section{Cultura visual, género y embalajes de juguetes de ciencia: ¿(Cómo) las niñas juegan a la ciencia?}

\author{
João Baliscei ${ }^{1}$ \\ Ana Carla Vagliati ${ }^{1}$
}

DOI: http://dx.doi.org/10.20435/serie-estudos.v26i57.1505

\begin{abstract}
Resumo: As representações de adultos/as sobre o que é considerado feminino e masculino reforçam estereótipos de gênero e, com isso, brinquedos, jogos e demais artefatos da cultura visual tendem a caracterizar meninos e meninas de formas diferentes. Como as identidades de gênero de meninas e meninos são representadas nos jogos infantis de ciência? As meninas aparecem nas embalagens desses jogos? Quando aparecem, como são apresentadas? Para responder a essas questões, neste artigo, de cunho documental e analítico, temos como objetivo problematizar as representações de ciência e feminilidade nas embalagens de jogos infantis. Para tanto, investigamos 38 embalagens de jogos infantis de ciência comercializados em 2017. Durante a análise, dividimos esse montante de embalagens em cinco grupos, os quais foram investigados sob fundamentos dos Estudos de Gênero e Estudos da Cultura Visual. Avaliamos que as embalagens de jogos científicos analisadas sugerem um "não protagonismo" feminino nos jogos de ciências. Constatamos, nesses artefatos, a ausência de endereçadores visuais que convidem as meninas a brincarem/fazerem ciência - ao menos que as atividades envolvam os cuidados com o corpo, os afazeres domésticos e a atuação como auxiliares.
\end{abstract}

Palavras-chave: educação; infância; visualidades.

Abstract: The representations of adults about what is considered feminine and masculine reinforce gender stereotypes and, therefore, toys, games, and other artifacts of visual culture tend to characterize boys and girls in different ways. How are the gender identities of girls and boys represented in children's science games? Do the girls appear on the packaging of these games? When do they appear, how they are presented? To answer these questions, in this documentary and analytical article, we aim to problematize the representations of science and femininity in children's games packaging. For this purpose, we investigated 38 packs of children's science games sold in 2017. During the analysis, we divided this amount of packs into five groups, which were

1 Universidade Estadual de Maringá (UEM), Maringá, Paraná, Brasil. 
investigated based on Gender Studies and Visual Culture Studies. We evaluated that the packaging of scientific games analyzed suggests a female "non-protagonism" in science games. We found, in these artifacts, the absence of visual routers that invite girls to play/do science, unless the activities involve taking care of the body, doing housework, and acting as assistants.

Keywords: education; childhood; visualities.

Resumen: Las representaciones de los/as adultos/as sobre lo que se considera femenino y masculino refuerzan los estereotipos de género y, por lo tanto, los juguetes, juegos y otros artefactos de la cultura visual tienden a caracterizar a niños y niñas de diferentes maneras. ¿Cómo se representan las identidades de género de niñas y niños en los juegos de ciencia? ¿Aparecen las chicas en el embalaje de estos juegos? ¿Cuándo aparecen, cómo se presentan? Para responder a estas preguntas, en este artículo documental y analítico, pretendemos problematizar las representaciones de la ciencia y la feminidad en los envases de juegos infantiles. Para ello, investigamos 38 embalajes de juegos de ciencia para niños/as vendidos en 2017. Durante el análisis, dividimos esta cantidad de paquetes en cinco grupos, que fueron investigados sobre la base de Estudios de Género y Estudios de Cultura Visual. Evaluamos que el empaquetado de los juegos científicos analizados sugiere un "no protagonismo" femenino en los juegos de ciencia. Encontramos, en estos artefactos, cierta ausencia de direccionadores visuales que inviten a las niñas a jugaren/hicieren ciencia, a menos que las actividades impliquen el cuidado del cuerpo, las tareas del hogar y actuar como asistentes.

Palabras clave: educación; infancia; visualidades.

\section{ENTRE SUJEITOS “BRILHANTES” E “ESFORÇADOS”}

No início de abril de 2017, o jornal Folha de São Paulo apresentou uma notícia com o título Meninas de 6 anos já não se acham inteligentes e desistem de atividade ${ }^{2}$, de autoria de Phillippe Watanabe. Lendo a matéria, tomamos conhecimento de que estes dados são produto de uma série de experimentos realizados com mais de 400 meninas e meninos com idade entre cinco e sete anos. O recorte etário se deve ao fato de que, segundo apontam cientistas, são nessas idades que ocorrem os processos de internalização de estereótipos de gênero. Segundo descreve a notícia, em um dos experimentos, os/as pesquisadores/as contaram para as crianças uma história sobre alguém "muito, muito inteligente", tendo cuidado para não dar pistas no que diz respeito à identidade de gênero dessa suposta pessoa inteligente. Solicitou-se às crianças, então, que associassem essa história a um dos/as adultos/as apresentados/as a elas, duas mulheres e dois homens. Observaram, pois, que as crianças com até cinco anos de idade associaram a "pessoa inteligente" ao próprio gênero, ou seja, as meninas escolheram uma das

\footnotetext{
${ }^{2}$ Mais informações em: http://migre.me/wnwDD
} 
mulheres adultas, e os meninos, um dos homens. Contudo, quando a escolha fora manifestada por crianças maiores, a partir dos seis anos de idade, verificaram-se que as meninas já não estavam mais tão propensas a escolher uma pessoa de seu gênero. Isso, por um lado, indica uma possível valorização da masculinidade e, por outro - como sugere o título da notícia -, que as meninas de seis anos já não consideram outras mulheres e a si mesmas tão inteligentes assim.

Para verificar se essa percepção sobre inteligência influenciava na constituição identitária das crianças, os/as pesquisadoras/es envolvidos/as no experimento apresentaram dois conjuntos de jogos. O primeiro grupo de jogos, segundo informaram às crianças, era destinado a pessoas "muito, muito inteligentes"; já o segundo grupo, destinado a pessoas "muito, muito esforçadas". Novamente, houve diferenças entre os interesses e comportamentos manifestados pelas crianças de cinco e de seis anos. Os meninos e meninas mais novos/as apresentaram interesse pelos jogos supostamente destinados a pessoas inteligentes; as meninas com mais de seis anos de idade, contudo, mostraram-se menos interessadas nesses tipos de jogos. Esses resultados foram considerados problemáticos pelos/as pesquisadores/ as, pois sugerem que, quando adultas, essas e outras meninas podem se afastar de atividades e profissões que socialmente são associadas à inteligência. Diante dessa notícia e dos dados que ela apresenta, recordamo-nos de outra pesquisa,

Em um estudo desenvolvido por Barbara Loyd e Gerard Duveen (2003), verificou-se que, desde os primeiros anos idade, meninos e meninas recebem representações e expectativas distintas conforme o gênero. As meninas são orientadas a interagir em brincadeiras e jogos mais calmos, enquanto os meninos são incentivados a participar de brincadeiras e a utilizar brinquedos agitados, evidenciando a influência dos jogos na internalização de gênero. A autora e o autor concluíram, pois, que quanto maior a idade das crianças, mais provável é que estejam internalizadas as marcas de gênero. Evidenciaram, ainda, a influência dos jogos nessa internalização de gênero, já que, desde bebês, meninos e meninas são incentivados/as a participar de brincadeiras e a utilizar brinquedos diferentes e generificados.

Considerando que as influências distintas sobre os gêneros podem envolver diversos estímulos e, em alguns momentos, a ausência deles, recordamos do estudo de Lindamir Salete Casagrande e Marilia Gomes Carvalho (2011), que explicam que a minoria feminina nas carreiras científicas e tecnológicas pode ser 
decorrente também da falta de estímulo de docentes, pais, mães e demais familiares para que as meninas, ainda durante a infância, dediquem-se a jogos, brincadeiras e atividades que envolvam as ciências exatas e naturais. Tais informações nos impulsionaram na busca por conhecer a realidade escolar de jovens meninas e verificar os seus desempenhos no que tange às disciplinas de Ciências, Leitura e Matemática. Para tanto, acessamos os resultados do Programa Internacional de Avaliação de Estudantes (PISA), realizado em 2015 em 13 países além do Brasil, sobre o desempenho de estudantes de 15 anos em Ciências, Leitura e Matemática. Em Ciências, os meninos tiveram desempenho superior ao das meninas, com exceção da Finlândia e da Coreia do Sul. Na avaliação de leitura, o desempenho das meninas foi superior ao dos meninos. Na avaliação de matemática, os resultados se invertem e, novamente, os meninos demonstram desempenho superior em relação às meninas.

Esse conjunto de estudos nos sugere que as representações de adultos/ as sobre o que é considerado feminino ou masculino, de certa forma, produzem e reforçam estereótipos que aproximam as meninas das ciências humanas, ao mesmo tempo que as distanciam das ciências naturais e exatas. Elas, portanto, tendem a se afastar da área das ciências exatas e naturais por não se considerarem inteligentes. Contudo convém ressaltar que, antes de não "se considerarem inteligentes", é bastante provável que essas meninas não "foram consideradas inteligentes" por sujeitos adultos. Quando adultos/as produzem e reforçam a representação de que "meninas não são boas com às ciências naturais e exatas", acabam pouco ou nada incentivando-as a se dedicar a essas áreas de conhecimento. Em vez de formular uma afirmativa que anuncie de modo categórico "meninos e meninas possuem desempenhos assimétricos nas ciências exatas e naturais", interessa-nos estruturá-la como questionamento: "por que meninos e meninas possuem desempenhos assimétricos nas ciências exatas e naturais?". A pergunta em questão se harmoniza com os Estudos de Gênero - que estão diretamente ligados à história do Movimento Feminista e compreende que as feminilidades e masculinidades são identidades (trans)formadas pela e na cultura.

A partir dos Estudos de Gênero, portanto, somos incentivados a pensar as assimetrias entre os desempenhos de meninos e meninas estudantes nas ciências naturais e exatas menos como um dado espontâneo e mais como resultado das ações (ou na falta de ações) que atravessam os corpos e comportamentos 
infantis. Nos espaços escolares, como explica Guacira Lopes Louro (1997), esses atravessamentos ocorrem, sobretudo, pela linguagem. Quando adultos/as recorrem unicamente ao uso de substantivos, adjetivos e pronomes masculinos para se referir ao conjunto de crianças, por exemplo, provocam, segundo a autora, uma ocultação do feminino. Os significados não anunciados (porém instituídos) pela escola acabam por ensinar à estudante menina que "[...] sempre que a professora disser que 'os alunos que acabarem a tarefa podem ir para o recreio' ela deve se sentir incluída. Mas ela está sendo, efetivamente, incluída ou escondida nessa fala?" (LOURO, 1997, p. 66). Tamanha é a internalização do ocultamento das mulheres na e pela linguagem que, como sublinha a autora, é comum depararmo-nos com mulheres adultas que se referem a si mesmas no masculino. Especificamente sobre as competências nas ciências exatas, a autora cita pesquisas que apontam que, quando um menino demonstra bom desempenho em matemática, é considerado "brilhante" ou "um aluno em potencial" por suas professoras e professores. Contudo tais palavras não foram utilizadas pelos/ as mesmos/as docentes para se referir a uma menina. Se o bom desempenho em matemática for alcançado por uma aluna, esta é descrita (e instituída) como "muito esforçada" ou "muito comportada".

Ademais, os artefatos que constituem os universos masculinos e femininos, desde a infância, indicam que, para além da escola, há um conjunto de currículos culturais que atua na (trans)formação das identidades de gênero de meninos e meninas. Nesse sentido, consideramos que, ao observarmos os significados que brinquedos, jogos e imagens endereçam às crianças, possivelmente, localizaremos pistas ou respostas à pergunta "por que meninos e meninas possuem desempenhos assimétricos nas ciências exatas e naturais?". É possível considerar que as visualidades intrínsecas aos brinquedos contribuem para as representações de gênero de meninos e meninas em sua primeira infância e, consequentemente, quando adultos/as, em suas decisões, medos e gostos quanto aos estudos e à profissão. Nesse ponto, somamo-nos aos Estudos da Cultura Visual, um campo de investigação que, assim como propõe Fernando Hernández (2007), apresenta interfaces com a epistemologia pós-estruturalista e com os Estudos de Gênero. Questionam as maneiras como os artefatos visuais, tais como o cinema, a publicidade, os materiais escolares, os desenhos infantis e as imagens da Arte, autenticam identidades específicas e, com isso, balizam os modos como os sujeitos percebem 
a si mesmos, os/as outros/as e o mundo onde vivem. Os Estudos da Cultura Visual compreendem, pois, as imagens não apenas em seu caráter estético; sublinham sua atuação como artefatos culturais, pedagógicos e políticos que têm sido utilizados, por exemplo, para prestar manutenção à hegemonia e, ao mesmo tempo, para reclamar por representatividade de grupos marginalizados.

Perguntamo-nos então: como as identidades de gênero de meninas e meninos são representadas nos jogos infantis de ciência? As meninas aparecem nas embalagens desses jogos? Quando aparecem, como são apresentadas? Para responder a essas questões, neste artigo de cunho documental e analítico, temos como objetivo problematizar as representações de ciência e feminilidade nas embalagens de jogos infantis. Para tanto, investigamos 38 embalagens de jogos infantis de ciência comercializados em 2017 e localizados em quatro sítios de jogos infantis: Clementoni, Estrela, RiHappy e Science4you - marcas cujos produtos são distribuídos nacional e internacionalmente. Chegamos a esse montante selecionando apenas aquelas embalagens de produtos apresentados como "jogos científicos" pelos sítios investigados. Antes de apresentar nossa análise, contudo, consideramos ser pertinente abordar aspectos teóricos e conceituais dos Estudos da Cultura Visual, relacionando-os com os Estudos de Gênero - campos de investigação que, como apresentamos até então, demonstram afinidades entre si.

\section{A CULTURA VISUAL PRODUZINDO GÊNEROS}

A partir de Hernández (2007), identificamos que os artefatos da cultura visual engendram visualidades que interpelam os indivíduos e buscam representá-los ou, pelo menos, promover identificações. Tais artefatos, que cada vez mais integram o cotidiano infantil, oferecem diferentes marcas sociais acerca das infâncias e, dentre elas, aquelas que descrevem e instituem gêneros específicos. Portanto atuam como Pedagogias Culturais - conceito abordado inicialmente por Shirley Steinberg e Joe Kincheloe (2001) e que implica pensar que a escola não é a única instituição capaz de conduzir processos educativos. A autora e o autor enfatizam que, por proporcionarem significações, os artefatos culturais também são, de certa forma, educativos e conferem conhecimentos específicos aos sujeitos.

Conforme explica Susana Rangel Vieira da Cunha (2008), as imagens produzem forte impacto sobre os indivíduos, por fazerem parte do acervo de sua memória. Assim, torna-se inadequado valer-se das imagens como artefatos neutros ou 
simplesmente responsáveis pela "decoração" de espaços ou pelo divertimento e prazer que acarretam. As imagens, como esclarece, "[...] modelam nossos modos de ver, narram o mundo a partir de determinados pontos de vista, territorializam tribos, constroem e disputam significados" (CUNHA, 2008, p. 107).

Muitos são os significados "disputados" visualmente, sendo que tais disputas envolvem grupos que defendem a manutenção de identidades hegemônicas e também grupos que reclamam por representatividades mais complexas e que contemplem identidades que são estigmatizadas socialmente. Megg Rayara Gomes de Oliveira (2017), por exemplo, compartilha aspectos de sua infância, quando ainda era identificada como uma pessoa cisgênero ${ }^{3}$, e quando sua pele negra e seu comportamento feminino - lido como inadequado para um menino - eram reiteradamente associados com a figura do diabo. Foi a partir do século IX, a partir de tradições cristãs, que a cor preta passou a ser associada ao mal, e no campo visual, representara-se a pele do diabo com tonalidade escura em contraste da pele branca dos/as anjos/as, santos/as e demais figuras sagradas. Anos posteriores, no século $\mathrm{XI}$, os costumes cristãos associam a prática homossexual também ao diabo. "Assim, as representações do Diabo, ora preto, ora bicha, ora preto e bicha, me foram apresentadas muito cedo, interferindo na maneira como eu me via e como eu me relacionava com outras pessoas" (OLIVEIRA, 2017, p. 16). Na escola, conforme a autora, ainda que a figura do diabo não fosse convocada nas imagens, exercícios e recursos didáticos, a repetição de figuras brancas e cisgênero atribuía protagonismo a certas identidades e invisibilizava outras.

Sobre a maneira como a cultura visual tem ou não representado identidades étnico-raciais, lembramo-nos dos estudos de Grada Kilomba (2019), que afirma que meninos e meninas negros/as acabam, muitas vezes, sendo forçados/as a se identificar com as imagens de pessoas brancas, porque as imagens de pessoas negras não costumam ser positivas. Em suas palavras:

Revistas, quadrinhos, filmes e televisão coagem a criança negra a se identificar com os outros brancos, mas não consigo mesma. A criança é forçada a criar uma relação alienada com a negritude, já que os heróis desses cenários são brancos e as personagens negras são personificações de fantasias

${ }^{3}$ Termo que abrange as pessoas que se identificam com o gênero que lhes fora atribuído antes ou no nascimento. Transgênero ou transexual, por sua vez, abrange pessoas que não se identificam, em diferentes graus, com o gênero que Ihe fora atribuído (JESUS, 2015). 
brancas. Apenas imagens positivas, e eu quero dizer imagens "positivas" e não "idealizadas", da negritude criadas pelo próprio povo negro, na literatura e na cultura visual, podem desmantelar essa alienação. (KILOMBA, 2019, p. 154).

As pesquisas mencionadas demonstram que, para além de produzir significados afetos às masculinidades e feminilidades, os artefatos da cultura visual estão comprometidos também com a caracterização e representação de outras questões identitárias, tais como a negritude e a branquitude; a cisgenereidade e a transexualidade; a infância, a velhice e a vida adulta; a homossexualidade, a heterossexualidade e as demais orientações sexuais etc.

Neste artigo, especificamente, interessamo-nos pelas feminilidades (e, consequentemente, pelas masculinidades) e pelos jogos de ciência. Como artefatos da cultura visual, os produtos endereçados às crianças têm sido tomados como objetos de análise por autores e autoras que se importam com as maneiras que os gêneros são discursiva e visualmente construídos. Juliet Schor (2009), por exemplo, analisa que desde meados do século XX, para a venda de produtos infantis, a publicidade tem empregado vozes, cores, ritmos e competências específicas conforme o gênero da criança. Hoje, segundo investiga, "[...] os temas antigos de desastres de carro para garotos e objetos cor-de-rosa para meninas não desapareceram, apenas são menos comuns, pois a diferenciação de gênero se tornou mais sutil" (SCHOR, 2009, p. 40). Márcia Aparecida Gobbi (2015), por sua vez, identifica reflexos das normativas de gênero nas maneiras como as crianças da Educação Infantil desenham e interagem com as cores. Observa que mais da metade dos quase 90 desenhos infantis coletados fazia uso da cor rosa e que, em todos eles, o rosa fora utilizado para identificar personagens femininos.

Os exemplos supracitados se harmonizam com o argumento de Nadia Geisa Silveira de Souza (2016) de que os corpos são elementos biossociais, já que são estruturados por fatores biológicos que sofrem intervenções da cultura, sendo, portanto, sutilmente fabricados. A escola, a família, a cultura e as práticas alimentícias, conforme explica, recorrem à linguagem na tentativa de descrever os corpos a partir de determinados gêneros, porém, com isso, acabam generificando-os, sutilmente. Como explica a autora:

[...] uma das primeiras curiosidades da gestação, além da saúde do feto, refere-se a pergunta: "será menino ou menina?". Na ecografia, diante da 
imagem da genitália do feto e da confirmação de que é, por exemplo, menina, aquele ser em desenvolvimento ingressa em um outro conjunto de práticas "invisíveis", agora, também da família. Para aquele ser, visto como menina, passa-se a comprar roupas rosa, bonecas, enfeites e a organizar um quarto de menina. E se for menino? Passa-se a comprar roupas que podem ter todas as cores, menos rosa, e brinquedos, que não incluam boneca. "Afinal, é um menino!". (SOUZA, 2016, p. 37).

Esse processo é reforçado também nas práticas escolares, nas falas de professores/as, nas filas, nas brincadeiras e nos jogos propostos nos intervalos, nos recursos didáticos e nos currículos escolares, contudo, como sublinha a autora, sua inauguração é anterior ao ingresso à escola e até mesmo ao nascimento do sujeito. Nesse sentido, jogos, cores, palavras, projeções e imagens selecionados pela família das crianças são artefatos da cultura visual potentes no que diz respeito à oferta de referências a partir das quais elas poderão constituir e viver sua identidade de gênero. Inspirados nesses e em outros referenciais, nós também temos nos dedicado a investigar as maneiras como masculinidades e feminilidades são (trans)formadas culturalmente. Filmes de animação da Disney (BALISCEI, 2020), os aspectos históricos e artísticos dos usos generificados da cor azul e da cor rosa (BALISCEI, 2021) e notícias contemporâneas (VAGLIATI; CALSA, 2017) foram alguns dos artefatos da cultura visual problematizados em nossas pesquisas e que podem ser somados a este artigo, em que propomos analisar 38 embalagens de jogos infantis de ciência.

\section{JOGOS DE CIÊNCIA E A PRODUÇÃO VISUAL DE FEMINILIDADES "ESFORÇADAS"}

Entre os jogos infantis que contribuem para a (trans)formação das identidades de gênero de meninos e meninas, encontramos, nos sítios das marcas Clementoni, Estrela, RiHappy e Science4you, aqueles identificados como "jogos científicos". Tendo em vista nossos interesses pelas imagens, debruçamo-nos sobre as visualidades das embalagens de 37 jogos e identificamos marcadores de gênero que pudessem (ou não) incentivar às meninas a brincar e, quem sabe, produzir, ciência. Chamaram-nos a atenção dois aspectos visuais que, pela repetição, foram adotados por nós como critério a partir dos quais as embalagens foram divididas e classificadas: a cor e a presença de figuras de meninos e meninas. 
Nesse ponto, sublinhamos que as crianças, independentemente de seu gênero, podem se identificar com o azul, com o rosa e com as demais cores. Contudo é preciso evidenciar que tal predileção cromática não é natural e espontânea e que a preferência e até mesmo a repulsa por determinadas cores são desenvolvidas conforme meninos e meninas são incentivados/as por seus/suas familiares, professores/as e pela cultura visual a consumirem artefatos - roupas, brinquedos, materiais escolares e alimentos - com cores específicas, e a rejeitar outros. Como explicamos em outro estudo, inclusive, antes do século XX, houve tempos e sociedades que associavam as crianças à cor branca, independentemente de seu gênero, e, ainda, outras que caracterizavam meninos e meninas de modos distintos, porém, justamente ao contrário daquilo que nos parece óbvio hoje, isto é, eles usavam rosa e elas azul (BALISCEI, 2021).

Nos Estados Unidos, como demonstra Jo B. Paoletti (2012), as características do século XX - tais como as reações conservadoras aos movimentos feministas, a alta manufatura de produtos, as novas concepções acerca da infância, a inserção das crianças em práticas de consumo e a popularização da ultrassonografia - contribuíram para que o azul e (principalmente) o rosa fossem utilizados não como simples cores quaisquer, mas como recursos estratégicos para (intentar) caracterizar e tornar os corpos das crianças masculinos e femininos, respectivamente. A autora se refere a esse processo como pinkification. No Brasil, semelhantemente, essa divisão cromática e generificada aparece, por exemplo, em celebrações de "chá de bebê"; mais recentemente, de "chá revelação"; e em pronunciamentos como aquele feito pela ministra da Mulher, da Família e dos Direitos Humanos, em janeiro de 2019. Tais práticas culturais não só reclamam para que "meninos usem azul" e "meninas usem rosa" como também contribuem para que, socialmente, o azul e o rosa - diferentemente das demais - sejam cores com potencialidades e funções sexistas.

Assim, como estratégia de apresentação das 38 embalagens de jogos científicos e das análises que tecemos sobre elas, dividimo-las em cinco grupos, tendo em vista, primeiro, as cores predominantes nas embalagens e, segundo, a presença ou não de figuras de meninos e meninas. A divisão por grupos, portanto, apresentou os seguintes critérios e configurações: 1: jogos com cores socialmente masculinas e sem figuras de pessoas (20 embalagens); 2: jogos com cores socialmente masculinas e com figuras de pessoas (meninos) (nove embalagens); 3 - jogos com 
figuras de pessoas (meninos e meninas) (seis embalagens); 4: jogos com cores socialmente femininas (duas embalagens); e 5: jogos com cores e visualidade neutras (uma embalagem). Em nossa busca, não encontramos embalagens que apresentassem apenas figuras de meninas brincando/fazendo ciência.

Identificamos como o grupo com maior quantidade de jogos o que tem por característica o uso de cores socialmente masculinas e a ausência de figura de meninos e meninas. Apesar de não fazer referência explícita e verbal às masculinidades, consideramos que os 20 jogos que integram o Grupo 1 são, provavelmente, endereçados aos meninos. Nossa inferência é justificada pelo uso generificado que, socialmente, tem sido atribuído à cor azul e às tonalidades de cinzas, como abordaremos mais adiante. Na Figura 1, apresentamos as 20 embalagens reunidas e destacamos duas delas que constituem o Grupo 1.

Figura 1 - Jogos com cores masculinas e sem figuras de pessoas (Grupo 1)
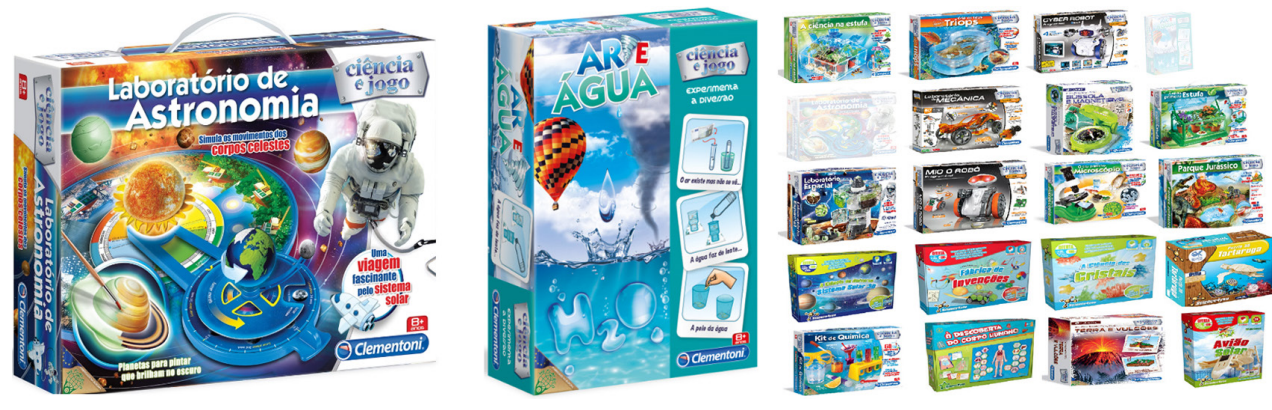

Fonte: Elaboração do autor e da autora com base em Rihappy (2017), Science4you (2017) e Clementoni (2017).

A obviedade do uso que contemporaneamente tem sido feito do azul na caracterização do masculino é contrastada, contudo, diante do estudo de Michel Pastoureau e Dominique Simonnet (2006), que argumentam que, antes do século XIX, essa mesma cor fora utilizada justamente em associação ao feminino. Em alusão à Virgem Maria - personagem que conforme o culto cristão vive no céu -, os investimentos pictóricos e iconográficos do Catolicismo instauraram a partir do século XII associações entre o azul, a feminilidade e a virgindade. Em suas palavras, a "[...] Virgem se converte na principal promotora do azul" (PASTOUREAU; SIMONNET, 2006, p. 22, tradução nossa). Esse aspecto histórico e generificado 
do azul apresentado pelos autores demonstra que a atribuição que fazemos às cores para designar qualquer grupo ou gênero não é arbitrária; ao contrário, carrega traços culturais e pode ser modificada conforme às necessidades, práticas e desejos sociais. Além do azul, há nas demais embalagens do Grupo 1 a recorrência ao cinza - tonalidade essa que, conforme teorizam Modesto Farina, Clotilde Peres e Dorinho Bastos (2006), remete à neutralidade e tende a ser associada ao cimento, máquinas e edificações. Ainda conforme a autora e os autores, na publicidade é comum o emprego do cinza em alusão à cor prata que, por sua vez, remete à modernidade, sofisticação e tecnologia. As sensações de tecnologia e de invenção intrínsecas ao cinza são reforçadas pelas imagens que ilustram as embalagens da Figura 2 e convidam às crianças - supostamente meninos - a viverem experiências com robôs, carros e mecânica, exaltando qualidades como velocidade, bravura e inteligência.

Figura 2 - Jogos com cores masculinas e sem figuras de meninos e meninas (Grupo 1)
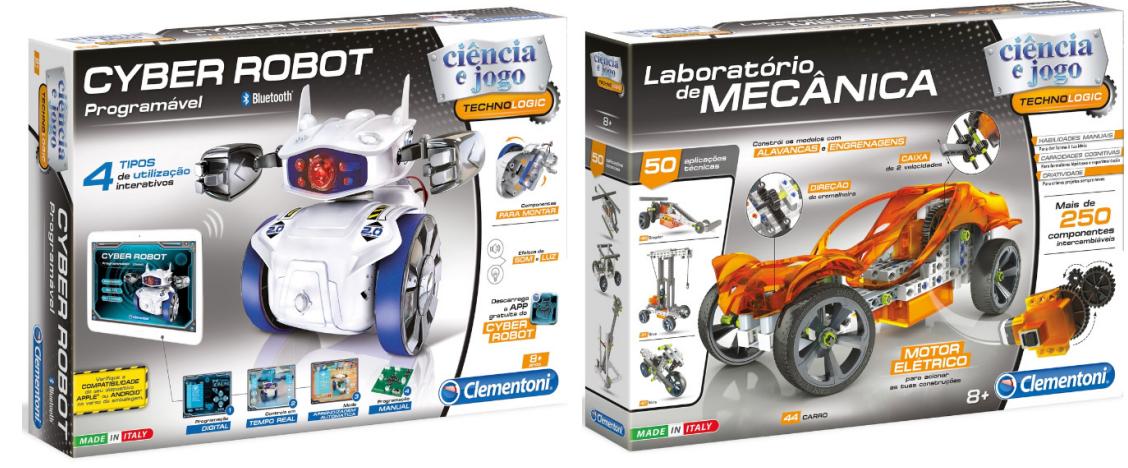

Fonte: Elaboração do autor e autora com base em Clementoni (2017).

As características dos jogos pretensamente destinados aos meninos nos remetem às conclusões do estudo de Constantina Xavier-Filha (2012), para quem os meninos são submetidos a um forte controle social de condutas e gostos para que se tornem "homens de verdade". Por essa razão, de acordo com a autora, os meninos relutam "[...] mais em desconstruir o modelo único de masculinidade hegemônica. Segundo alguns deles, um menino mais sensível seria considerado homossexual" (XAVIER-FILHA, 2012, p. 644). 
As nove embalagens de jogos científicos do Grupo 2, por sua vez, além de cores específicas, sobretudo em tons azulados, recorrem ao uso de figuras de pessoas - todos meninos, como exemplificamos na Figura 3 a seguir, na qual destacamos também duas embalagens. Uma leitura possível de ser feita é que tais embalagens demarcam a quem os produtos (e a ciência) são destinados. Além disso, reforçam a hipótese que levantamos quando analisamos as embalagens do Grupo 1, a de que, quando se opta por usar a cor azul em um produto, provavelmente, ele é endereçado a sujeitos do gênero masculino; afinal, no Grupo 2, só há figuras de meninos.

Figura 3 - Jogos com cores masculinas e com figuras de meninos (Grupo 2)
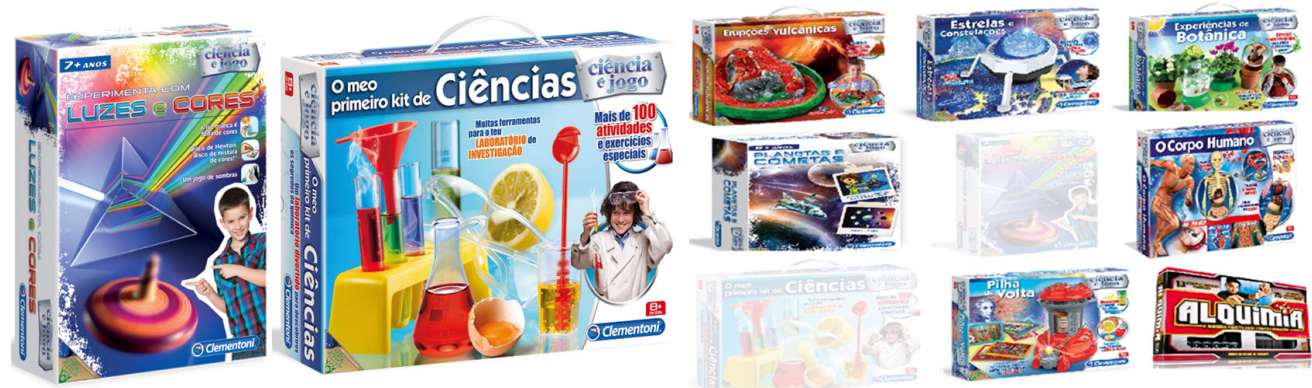

Fonte: Elaboração do autor e da autora com base em Clementoni (2017) e Rihappy (2017).

Consideramos, ainda, que os meninos das embalagens em questão reproduzem estereótipos de masculinidade, já que são todos brancos e usam roupas tipicamente associadas ao masculino, como jalecos, gravatas, camisetas em tons fortes, com estampas ou listras, por exemplo. Além das figuras de meninos, há, também, em três embalagens que integram o Grupo 2, um personagem masculino estilizado, no jogo "Planetas e Cometas"; um corpo humano dissecado, apresentando anatomia e musculatura de um homem adulto, em "O corpo humano"; e uma representação do físico italiano Alessandro Volta (1745-1827), em "Pilha de Volta" - jogo baseado em sua invenção: a primeira pilha elétrica.

Se aproximarmos as embalagens que integram os Grupos 1 e 2, perceberemos que há nelas uma espécie de "estética masculinizante", a qual reúne imagens, cores, formas, tipografias, sensações e linhas que indicam suposto endereçamento aos meninos. Ao analisar significados de embalagens de produtos, Marina Chinen 
(2005, p. 10) sublinha que "[...] linhas retas, ângulos e vértices estão associados à rigidez, à firmeza e à masculinidade. Curvas e ondulações expressam dinamicidade, sensualidade e feminilidade". Essa estratégia do design aparece também nas embalagens: primeiro, nos raios, explosões, sensações de movimentos e aparatos representados com linhas retas e rígidas; e, segundo, nas letras dos títulos e enunciados constituídos por linhas quebradas, retas e com arestas marcadas em associação ao risco, aventura, velocidade e à masculinidade. As 20 embalagens do Grupo 1 e as nove do Grupo 2, ao negarem a presença feminina nas atividades de pesquisa científica de áreas exatas e da natureza, sutilmente, descrevem e instituem um cenário em que a presença feminina é anulada, como se meninas não pudessem brincar de fazer ciência e como se a própria ciência não tivesse sido construída, também, por pesquisadoras mulheres.

O Grupo 3 reúne seis jogos cujas embalagens contêm representações de pessoas, sendo elas meninos e meninas - o que pode sugerir que tais produtos são endereçados, indiscriminadamente, a qualquer gênero, e que ambos, meninos e meninas, podem brincar e fazer ciência. Contudo, quando examinamos atentamente as embalagens, percebemos que o emprego das cores e a disposição dos e das personagens retratados/as demarcam, sutilmente, a divisão de gênero e o público que buscam alcançar. Como indicam as embalagens da Figura 4, referentes ao Grupo 3, os jogos, predominantemente, recorrem à cor azul. Além disso, como pode ser percebido nas duas embalagens que destacamos, tais artefatos da cultura visual situam os meninos em posições privilegiadas, de evidência e protagonismo em relação às meninas.

Figura 4 - Jogos com figuras de meninos e meninas (Grupo 3)
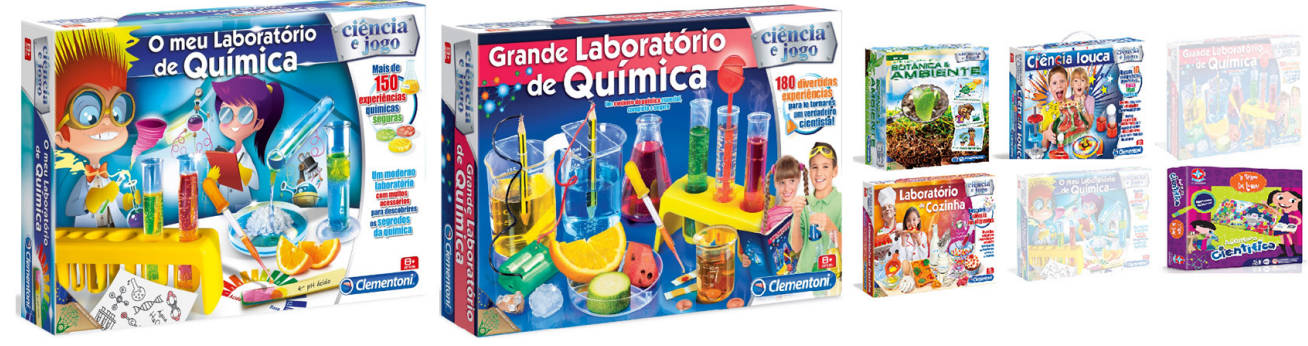

Fonte: Elaboração do autor e da autora com base em Clementoni (2017) e Estrela (2017). 
Eles inventam, criam e lideram, enquanto as meninas se mostram admiradas, "posam", sorrindo, e prestam anotações sobre aquilo que eles fazem. Assim, esses artefatos da cultura visual, como pedagogias culturais, autorizam que meninos e meninas brinquem e façam ciência, contudo, assumindo papéis diferenciados entre si. Do Grupo 3, apenas duas embalagens utilizam as cores rosa e roxo com predominância e colocam as meninas em primeiro plano, como indicam outras duas (Figura 5). Em uma delas, a personagem Luna ocupa parte significativa da embalagem e segura um livro em uma de suas mãos. Tem seu nome estampado da parte superior e na lateral do produto, o que lhe concede evidente protagonismo como menina que brinca/faz ciência. Contudo, na outra embalagem, as brincadeiras científicas não parecem envolver experimentos químicos, físicos, óticos e tampouco utilizar-se de acessórios e instrumentos de laboratórios. Tendo cores socialmente tidas como "femininas", a promessa do produto - como enuncia uma das frases impressas na embalagem - gira em torno de "descobrir a ciência dos alimentos" e localiza a menina-cientista em meio a ingredientes tais como ovos, leite, peneira e fouet. Além disso, apesar de a menina ocupar o primeiro plano central, é o garoto quem segura o bolo e quem usa o chapéu de chefe como sinal de uma possível hierarquia e do poder que ele, enquanto menino, desempenha naquele espaço.

Figura 5 - Jogos com figuras de meninos e meninas (Grupo 3)
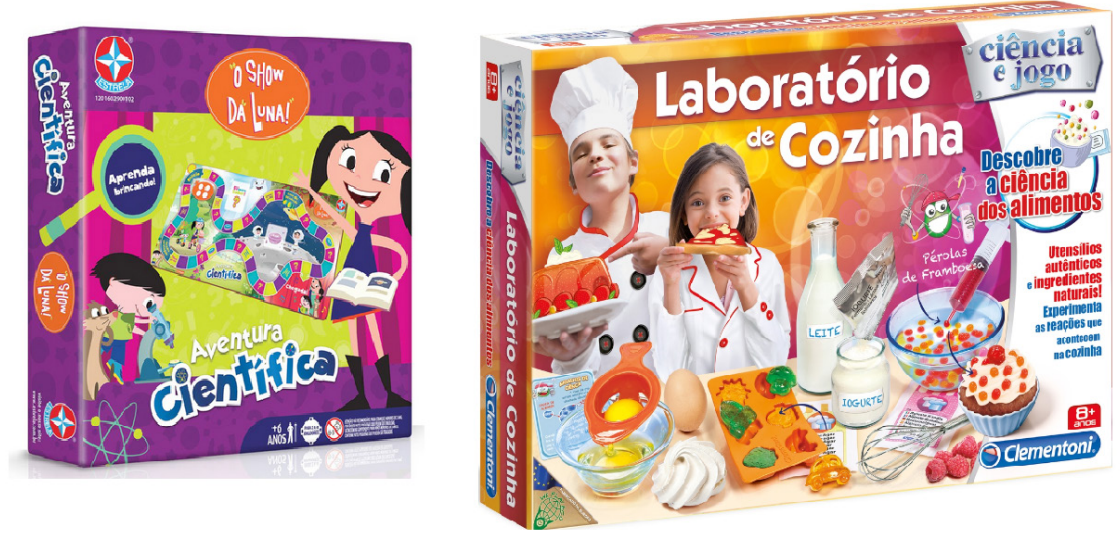

Fonte: Elaboração do autor e da autora com base em Clementoni (2017) e Estrela (2017). 
Evidenciamos, assim, que, dentre as seis capas de caixas que compõem o Grupo 3, apenas uma evidencia e convoca a figura feminina para assumir protagonismo na brincadeira científica. Cinco das seis embalagens reportam-se a estereótipos de gênero, segundo os quais meninos seriam "naturalmente" inteligentes, curiosos e líderes - por isso precisam brincar com jogos que possibilitem explorar essas características - e meninas seriam "naturalmente" calmas, delicadas e atenciosas - daí devem brincar de culinária ou desempenhar papéis de assistentes coadjuvantes.

Tais imagens remetem-nos aos estereótipos de gênero observados no estudo de Loyd e Duveen (2003), em que foram investigados os comportamentos de mulheres enquanto brincavam com bebês de dez meses, que lhes eram desconhecidos/as. Num primeiro momento, os/as bebês usavam um macacão rosa e, após serem retirados/as de cada mulher, eles/as eram reapresentados/as a elas, desta vez, vestindo um macacão azul. Observando as ações das mulheres adultas, fora constatada forte relação entre o suposto sexo biológico dos/as bebês (indicado pela cor do macacão que ele/a usava) e os brinquedos que lhes eram oferecidos: quando o/a bebê usava roupa rosa e, por isso, "parecia" ser uma menina, as brincadeiras orientadas eram mais calmas. Por outro lado, quando o/a mesmo/a bebê era reapresentado/a com macacão azul e "parecia" ser um menino, era incentivado/a a interagir de maneiras mais agitadas e movimentadas. De certa forma, as expectativas e regulações dos/as adultos/as de que, por serem meninas, as crianças devem participar de brincadeiras que pouco ou nada envolvam força, velocidade, iniciativa e risco reapresentam-se também nas embalagens do Grupo 3 e nas figuras femininas "assistentes" de meninos cientistas.

O Grupo 4 é integrado por duas embalagens de jogos científicos que, em comum, fazem uso de cores e estéticas associadas às meninas, porém, sem trazer nenhuma pessoa ou personagem feminina. Ambas são apresentadas na Figura 6. São embalagens predominantemente rosa e laranja que propõem (provavelmente às meninas) que brinquem de ciência - porém - com um adendo: confeccionando sabonetes e velas, respectivamente. A isso lemos que há, novamente, uma distinção entre os produtos e jogos endereçados aos meninos e às meninas. Interpretamos que os sabonetes e velas remetem às profissões e atividades que tradicionalmente são associados às mulheres, como a limpeza, o cuidado com espaços domésticos, o esoterismo e a superstição. 
Figura 6 - Jogos com cores femininas (Grupo 4)
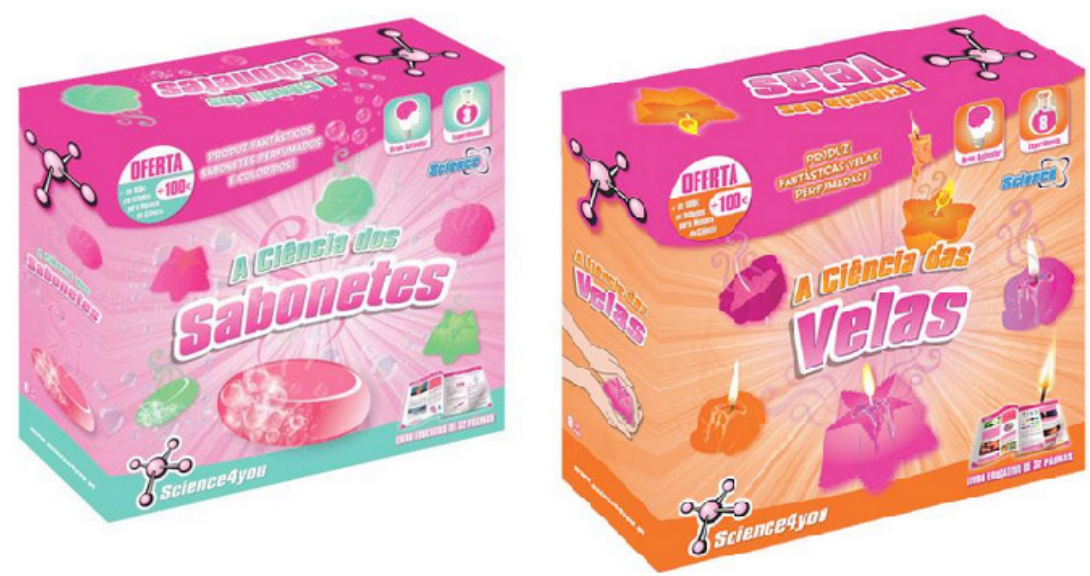

Fonte: Elaboração do autor e da autora com base em Science4you (2017).

Diante das embalagens do Grupo 4, lembramo-nos daquilo que Grayson Perry (2016) se refere como Redemoinho Vestigial - uma espécie de linguagem feminilizante que os/as designers adotam na criação de produtos endereçados a mulheres e meninas. Segundo o autor, essa caracterização do feminino pode ser facilmente localizada e "[...] consiste em uma linha arabesca, uma espiral, várias firulas e uma flor. Em sua versão mais enjoativa, há um coração e uma borboleta voando perto" (PERRY, 2016, p. 57, tradução nossa).

Nas embalagens deste grupo, a estética do redemoinho vestigial e a "evocação" da beleza podem ser identificadas no tom pastel, nas bolhas de sabão, nas formas de estrela e flor que as velas assumem e, ainda, nas linhas onduladas que saem desses dois elementos indicando seus possíveis aromas. É a partir dessa linguagem feminilizante da qual os meninos são ensinados a se distanciar que supomos que "A ciência dos sabonetes" e "A ciência das velas" são jogos endereçados às meninas. Sobre isso, junto de Perry (2016), lembramos do caso do menino estadunidense Grayson Bruce, que, em 2014, então com nove anos, fora ridicularizado e agredido por outros estudantes por levar à escola uma mochila dos personagens de My Little Pony - um desenho popular entre as meninas. Surpreende-nos, nesse caso em específico, que, como relata o autor, a escola não só não advertiu os agressores como também recomendou à vítima que não fizesse uso de mochilas e demais materiais considerados femininos. 
Casos semelhantes a esse também ocorrem em escolas e universidades brasileiras, como nos mostra Susana Rangel Vieira da Cunha (2010). Em uma pesquisa com crianças de até seis anos, pediu-se que separassem um conjunto de artefatos infantis entre o que era considerado de menino, de menina, e o que poderia ser dos dois. A autora descreve que "[...] durante esta atividade, surgiu a palavra gay. Uma menina disse que se um menino usasse a mochila rosa, da Barbie, ele seria diferente, um gay" (CUNHA, 2010, p. 18). Os casos exemplificados pelo autor e pela autora não só demonstram agressões aos meninos que se arriscam a gostar/ consumir aquilo que é tido como feminino como também as maneiras como tais produtos aprisionam meninas em estereótipos pouco complexos relacionados à beleza, à decoração, ao doméstico e ao cuidado.

Por fim, sobre a única embalagem que integra o Grupo 5, avaliamos que, de certa forma, ela foge aos critérios que estabelecemos para agrupar o nosso corpus de análise, tendo em vista, primeiro, que não apresenta figuras de meninos e meninas e que utiliza de cores, por vezes, consideradas "neutras" na identificação dos gêneros, como destacamos na Figura 7.

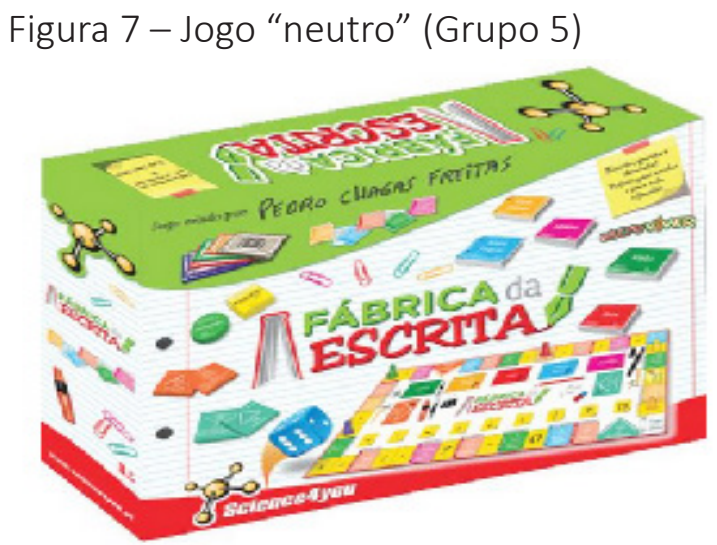

Fonte: Elaboração do autor e da autora com base em Science4you (2017).

Nela, há predominância do vermelho e do verde, e ainda que o rosa seja utilizado na composição do tabuleiro, conforme ilustrado, a cor é intercalada com outras, constituindo uma paleta relativamente neutra no que tange aos gêneros. 
Tendo em vista que os artefatos da cultura visual destinados ao público infantil buscam, por meio de cores e desenhos, interpelar seus/suas consumidores/as (PAOLETTI, 2012; GOBBI; 2015; BALISCEI, 2021), consideramos que essa embalagem não faz distinção entre os sujeitos que podem brincar e fazer ciências. Sugere, portanto, que fazer ciência não é uma atividade que requer uma identidade de gênero específica e que tanto meninos quanto meninas podem - inclusive juntos/as - brincar de "fabricar a escrita", como anuncia o título do jogo.

\section{CONSIDERAÇÕES FINAIS}

Buscamos demonstrar, ao longo deste estudo, que as imagens são portadoras e produtoras de significações e, dentre elas, aquelas que intensificam a dicotomia entre os gêneros e a fixação de identidades. A partir dos estudos de Gênero e Estudos da Cultura Visual, as imagens, aqui, não foram abordadas como simples componentes e acessórios que conferem "beleza" às embalagens; ao contrário, foram os principais alvos de nossa problematização. Enquanto artefatos da cultura visual que promovem pedagogias culturais específicas, as embalagens dos jogos científicos analisadas por nós não só descrevem como também instauram representações de gênero e de ciência.

Avaliamos que todas as embalagens analisadas neste estudo buscam demarcar seu público-alvo pelo uso e pela predominância de cores e pela recorrência de figuras masculinas e/ou femininas. Desta forma, sutilmente, classificam os jogos e as brincadeiras de ciências tomando o gênero como critério e sugerem que essa atividade deve ser desempenhada por sujeitos e modos restritos. Lembramo-nos, portanto, dos estudos de Jaqueline Gomes de Jesus (2015, p. 52), em que sublinha que a identidade de gênero é uma construção e que, como "[...] as influências sociais não são totalmente visíveis parece para nós que as diferenças entre homens e mulheres são 'naturais', totalmente biológicas, quando, na verdade, boa parte delas é influenciada pelo convívio social". Logo, é possível supor que o desempenho assimétrico que meninos e meninas têm no que diz respeito às ciências exatas e naturais, por exemplo, não é consequência de suas capacidades e limitações inatas e próprias ao gênero, mas sim resultados dos processos que descrevem (e produzem) masculinidades e feminilidades a partir de adjetivos, habilidades e visualidades específicas. 
Diante dos cinco grupos que analisamos, é importante mencionar que a ordenação da apresentação deles levou em conta a quantidade de jogos, sendo o Grupo 1 integrado por 20 jogos; o Grupo 2, por nove jogos; o Grupo 3, por seis jogos; o Grupo 4, por dois jogos, e o Grupo 5, com 1 jogo. Para além das análises qualitativas que desenvolvemos no corpo deste artigo, pensamos que os dados apresentados sugerem, também, desigualdades de gênero em nível quantitativo. Apontam que são os meninos quem podem brincar/fazer de ciências, já que, das 38 embalagens (100\%), $33(86,84 \%)$ são compostas por cores predominantemente associadas ao masculino, e apenas duas (10,52\%) por cores associadas ao feminino. Além disso, no que diz respeito ao uso de figuras de pessoas, das 15 embalagens (100\%) que atendem a esse critério, todas (100\%) apresentam sujeitos masculinos - em 11 (73,33\%) delas, há apenas figuras de meninos ${ }^{4}$. Apenas quatro (26,66\%) das embalagens trazem figuras de meninas - nestes casos, sempre acompanhadas de meninos. Não localizamos nenhuma embalagem composta apenas com figuras de meninas, tampouco uma que apresente o nome ou referência a uma cientista mulher ${ }^{5}$.

No entanto, apesar do pouco incentivo para que meninas e mulheres se interessem e permaneçam no campo científico, chamamos a atenção para os livros "Las chicas son de ciências: 25 científicas que cambiaron el mundo"6, de Irene Cívico e Sergio Parra (2018), e "Coisa de Menina"7, de Pri Ferrari (2016). Neles, demonstra-se, ao contrário das pedagogias culturais que as embalagens aqui analisadas sugerem, que as mulheres também fazem ciência.

Ao chegarmos à conclusão de que as embalagens de jogos científicos sugerem o "não protagonismo" feminino nos jogos de ciências, constatamos, nesses artefatos, a ausência de endereçadores visuais que convidem as meninas a brincarem/fazerem ciência - ao menos que as atividades envolvam os cuidados

\footnotetext{
${ }^{4}$ Aqui, incluímos também duas outras embalagens, uma que apresenta a figura de um corpo humano masculino dissecado, e outra que apresenta uma figura em alusão ao físico italiano Alessandro Volta.

5 O jogo "Pilha de Volta" faz referência ao invento de Alessandro Volta.

6 O livro apresenta 25 mulheres cientistas ao redor do mundo, e que suas descobertas e invenções se concentram nas mais diferentes áreas, como a da matemática, da biologia, da química, da física, da medicina, da astronomia, da oftalmologia e da neurociência.

7 O livro indica que meninas também se interessam por pilotar aviões, por arqueologia, mecânica e por química, por exemplo, e que batem recordes em atividades esportivas.
} 
com o corpo, os afazeres domésticos e a atuação como auxiliares. Consideramos, por fim, que a educação escolar, ao expor as crianças aos diversos artefatos da cultura visual, inclusive aos jogos de ciências aqui discutidos, ensina-lhes sobre comportamentos e contribui para a (trans)formação das identidades de gênero. Enquanto espaço de educação e formação, a escola e os/as profissionais que nela atuam podem também desestabilizar tais artefatos e os valores hegemônicos que eles autorizam, questionando-os, problematizando-os e subvertendo-os. Para tanto, faz-se necessário que professores/as entendam a complexidade de suas práticas e possibilitem cores, brincadeiras e jogos não dicotômicos para meninas e meninos.

\section{REFERÊNCIAS}

BALISCEI, João Paulo. Não se nasce azul ou rosa, torna-se: cultura Visual, gênero e infâncias. Salvador: Devires, 2021.

BALISCEI, João Paulo. PROVOQUE: cultura visual, masculinidades e ensino de artes visuais. Rio de Janeiro: Metanoia, 2020.

SCIENCE4YOU. Site da Science4you, 2017. Brinquedos e jogos educativos. Disponível em: https://brinquedos.science4you.pt/. Acesso em: 20 abr. 2017.

CASAGRANDE, Lindamir Salete; CARVALHO, Marilia Gomes. Desempenho escolar em Matemática: o que o gênero tem a ver com isso? In: CASAGRANDE, Lindamir Salete; LUZ, Nanci Stancki; CARVALHO, Marília Gomes (Org.). Igualdade na diversidade: enfrentando o sexismo e a homofobia. Curitiba: UTFPR, 2011.

CHINEM, Marina Jugue. As variantes sígnicas da embalagem: as relações da percepção no processo intersemiótico na construção dos estímulos táteis e visuais. In: CONGRESSO BRASILEIRO DE CIÊNCIAS DA COMUNICAÇÃO, INTERCOM, 28., set. 2005., Rio de Janeiro. Anais [...]. Rio de Janeiro, 2005.

CÍVICO, Irene; PARRA, Sergio. Las chicas son de ciências: 25 científicas que cambiaron el mundo. Barcelona: Penguin Random House Grupo Editorial, 2018.

CLEMENTONI. Site da Clementoni, 2017. Every world you can imagine. Disponível em: https://www.clementoni.com/pt/. Acesso em: 20 abr. 2017.

CUNHA, Susana Rangel Vieira. Menin@s nas tramas da cultura visual. In: BUSSOLETTI, Denise; MEIRA, Mirela (Org.). Infâncias em passagens. Pelotas: UFPel, 2010. p. 55-78. 
CUNHA, Susana Rangel Vieira. Infância e cultura visual. In: ASSOCIAÇÃO NACIONAL DE PÓS-GRADUAÇÃO E PESQUISA EM EDUCAÇÃO, 31., out. 2008, Caxambu. Anais [...]. Caxambu, 2008.

ESTRELA. Site da Estrela, 2017. Brinquedos Estrela. Disponível em: https://www.estrela. com.br/. Acesso em: 20 abr. 2017.

FARINA, Modesto; PEREZ, Clotilde; BASTOS, Dorinho. Psicodinâmica das cores em Comunicação. 5. ed. rev. e ampl. São Paulo: Edgard Blücher, 2006.

FERRARI, Pri. Coisa de Menina. São Paulo: Companhia das Letrinhas, 2016.

GOBBI, Marcia Aparecida. Lápis vermelho é de mulherzinha: vinte anos depois. In: FINCO, Daniela; GOBBI, Marcia Aparecida (Org.). Creche e feminismo: desafios atuais para uma educação descolonizadora. Campinas: Edições Leitura Crítica, 2015. p. 137-62.

HERNÁNDEZ, Fernando. Catadores da cultura visual: transformando fragmentos em nova narrativa educacional. Tradução de Ana Duarte. Porto Alegre: Mediação, 2007.

JESUS, Jaqueline Gomes. Homofobia: identificar e prevenir. Rio de Janeiro: Metanoia, 2015.

KILOMBA, Grada. Memórias da plantação: episódios de racismo cotidiano. Rio de Janeiro: Cobogó, 2019.

LLOYD, Barbara; DUVEEN, Gerard. Un análisis semiótico del desarrollo de las representaciones sociales de género. In: CASTORINA, J. A. Representaciones sociales: problemas teóricos y conocimientos infantiles. Barcelona: Gedisa, 2003.

LOURO, Guacira Lopes. Gênero, sexualidade e educação: uma perspectiva pósestruturalista. Petrópolis: Vozes, 1997.

OLIVEIRA, Megg Rayara Gomes. O Diabo em forma de gente: (re)existências de gays afeminados, viados e bichas pretas na educação. 2017. Tese (Doutorado em Educação) - Universidade Federal do Paraná, Curitiba, PR, 2017.

PAOLETTI, Jo B. Pink and Blue: telling the boys from the girls in America. Bloomington: Indiana University Press, 2012.

PASTOUREAU, Michel; SIMONNET, Dominique. Breve historia de los colores. Barcelona: Ediciones Paidós Ibérica, 2006.

PERRY, Grayson. La caída del hombre. Barcelona: Malpaso Ediciones, 2016. 
RIHAPPY. Site da Ri happy, 2017. Ri happy brinquedos. Disponível em: https://www. rihappy.com.br/. Acesso em: 20 abr. 2017.

SCHOR, Juliet B. Nascidos para comprar: uma leitura essencial para orientarmos nossas crianças na era do consumismo. Tradução de Eloisa Helena de Souza Cabral. São Paulo: Editora Gente, 2009.

SOUZA, Nadia Geisa Silveira. Discutindo práticas implicadas na produção do corpo. In: CAMOZZATO, Viviane Castro; CARVALHO, Rodrigo Saballa; ANDRADE, Paula Deporte (Org.). Pedagogias Culturais: a arte de produzir modos de ser e viver na contemporaneidade. Curitiba: Appris, 2016. p. 33-52.

STEINBERG, Shirley R.; KINCHELOE, Joe L. Sem segredos: cultura infantil, saturação de informações e infância pós-moderna. In: STEINBERG, Shirley R.; KINCHELOE, Joe L. (Org.). Cultura infantil: a construção corporativa da infância. Rio de Janeiro: Civilização Brasileira, 2001. p. 9-52.

VAGLIATI, Ana Carla; CALSA, Geiva Carolina. Lugar de menina é na ciência e onde ela quiser: representações em jogos infantis de ciências. In: SEMINÁRIO BRASILEIRO DE ESTUDOS CULTURAIS E EDUCAÇÃO, 7; SEMINÁRIO INTERNACIONAL DE ESTUDOS CULTURAIS E EDUCAÇÃO, 4., jun. 2017, Canoas. Anais [...]. Canoas, 2017.

XAVIER-FILHA, Constantina. A menina e o menino que brincavam de ser...: representações de gênero e sexualidade em pesquisa com crianças. Revista Brasileira de Educação, Rio de Janeiro v. 17, n. 51, p. 627-46, 2012.

\section{Sobre os autores:}

João Baliscei: Doutor e mestre em Educação pela Universidade Estadual de Maringá (UEM). Especialista em Arte-Educação e em Educação Especial pelo Instituto de Estudos Avançados e Pós-Graduação (ESAP). Graduado em Artes Visuais pelo Centro Universitário de Maringá (Unicesumar). Professor no curso de Artes Visuais na UEM e coordenador do Grupo de Pesquisa em Arte, Educação e Imagens (ARTEI). Desenvolve pesquisas sobre Educação, Arte/Ensino de Arte; Estudos Culturais; Estudos da Cultura Visual; Visualidades; Gênero e Masculinidades. E-mail: jpbaliscei@uem.com, Orcid: https://orcid.org/0000-0001-8752-244X

Ana Carla Vagliati: Doutora em Educação pela Universidade Estadual de Maringá. Mestra em Educação pela Universidade Estadual do Oeste do Paraná (UNIOESTE). Pedagoga pela UNIOESTE. Tem experiência na área de Educação, com ênfase na 
Educação Infantil, Graduação e Pós-Graduação. Desenvolve pesquisa em temas que envolvem representações sociais, formação docente e violência sexual. E-mail: ac.vagliati@hotmail.com, Orcid: https://orcid.org/0000-0002-8527-8663

Recebido em: 29/08/2020

Aprovado em: 28/03/2021 